\title{
An iterative method for estimating solute travel times to ditch drains under steady recharge and ponded conditions
}

\author{
Gautam Barua • M. K. Patidar
}

Received: 13 March 2014/Accepted: 16 November 2014/Published online: 14 January 2015

(c) The Author(s) 2015. This article is published with open access at Springerlink.com

\begin{abstract}
An iterative procedure is worked out for estimating solute travel times in a subsurface system by making use of the velocity and streamline distributions pertinent to the system. The developed method is then being applied to study the solute travel times to ditch drains originating from a field being subjected to a uniform (1) recharge and (2) ponding field over the surface of the soil. For case (1), both single and layered soils are being considered to estimate the travel times. The developed mathematical procedure is simple to use, robust, reasonably accurate even if being used with a lesser division of a streamline and completely eliminates the necessity of determination of any integrals for estimating the travel times-integrals which, in the methods generally been employed for estimating the travel times from steady-state analytical groundwater models, would otherwise need be evaluated. The study shows that travel times of water particles traversing through a layered soil being subjected to a uniform recharge at the surface are sensitive to the directional conductivities, anisotropy ratio (defined here as the ratio between horizontal and vertical hydraulic conductivities of soil) and thickness of individual layers of a soil profile as well as to the magnitude of the steady-state recharge on the surface of the soil. For the ponded drainage scenarios also, directional conductivities and thickness of a soil profile, extent of partial penetration and width of the ditch drains, levels of water head at the surface of the soil as well as on the ditches are observed to influence the travel
\end{abstract}

G. Barua $(\bowtie) \cdot$ M. K. Patidar

Department of Civil Engineering, Indian Institute of Technology

Guwahati, Guwahati 781 039, Assam, India

e-mail: g_barua@iitg.ernet.in

M. K. Patidar

e-mail: mukeshkrpatidar@gmail.com times in a noticeable way. The proposed method is important as it provides simple and accurate estimations of migration times of pollutants to subsurface drains under different drainage situations; it can also be used to assess the time of reclamation of a salt-affected or waterlogged soil being drained by a network of subsurface drains being installed for the purpose from the available hydraulic theory relevant to the concerned drainage situation.

Keywords Fluid travel times - Subsurface drains . Anisotropy ratio - Directional conductivities of soil

\section{Introduction}

An accurate estimation of groundwater travel times in an artificially drained watershed is essential to study the impact of drainage on the hydrologic aspects of the watershed. Subsurface drains are installed for increasing crop yields in seasonally or perennially wet soils with high productivity (Brown et al. 1998; Davis et al. 2000). However, numerous studies have shown that artificial drainage of an agricultural watershed brings about an increase in the outflow of streams in contact with the subsurface drainage tiles in the watershed and that a subsurface drainage system affects mostly the base flow portion of a stream hydrograph (Schilling and Libra 2003; Kladivko et al. 1999, 2004; Schilling and Helmers 2008; Schilling et al. 2012), particularly during fallow seasons when most of the drain tiles are running relatively full as compared to cropped seasons. Another central feature of a subsurface drainage system in a watershed is its influence on the groundwater travel times of a watershed. An accurate estimation of this parameter in a watershed is crucial as it provides information about probable time of migration of a pollutant to receiving water 
bodies in contact with the watershed via the subsurface (Jury 1975a, b; Jury and Weeks 1978) drains. Groundwater travel times are also a vital indicator for lag time of a management practice being introduced in a field. By lag time, we mean the time between initiation of a conservation practice in a watershed and a response being observed in the field because of this practice (Meals and Dressing 2006; Schilling and Wolter 2007). Subsurface drainage is also often used for reclaiming waterlogged and saline soils and in mitigating phosphorous and pesticide loads of agricultural fields (Youngs 1994; Dils and Heathwaite 1999; Heathwaite and Dils 2000; Kroger et al. 2008). Washing of a salt-affected soil often involves subjecting the surface of the soil to a uniformly recharged or ponded field so that sufficient head is being provided to force water though the soil profile with the intention that the moving water takes away a portion of the salt present in the soil profile, the salt-enriched water is then drained with the help of a network of subsurface drains put into the soil for the purpose (Martinez Beltran 1978; Rao and Leeds-Harrison 1991; Youngs 1994; Barua and Tiwari 1995; Youngs and Leeds-Harrison 2000; Barua and Alam 2013). Thus, during reclamation of a contaminated soil profile also, an accurate estimation of groundwater travel times for water particles originating at different locations on the surface of the soil is essential as this distribution provides information based on which the time of leaching of a contaminated soil profile may be worked out. It should be noted that this distribution is mostly non-uniform with particles being released further away from the drains taking much more time to move to the drains as compared to particles seeping from surficial locations close to drains (Zaslavsky 1979; Rao and LeedsHarrison 1991; Youngs and Leeds-Harrison 2000; Chahar and Vadodaria 2011). Groundwater travel times are frequently estimated for a hydrogeology setting by numerical means using numerical codes like MODFLOW and GFLOW (Haitjema 1995). However, the procedure requires detailed information about the flow boundaries as well as on the hydro-geological properties of the studied subsurface system (Schilling and Wolter 2007). Moreover, for better accuracy, particularly in regions where the flow characteristics change rapidly in a flow domain, the numerical codes require finer grid settings to be implemented which may, at times, be quite computationally demanding. The groundwater travel times of a watershed can also be estimated in a simple way by taking resort to a geographical information system (GIS) platform, as has been done by Schilling and Wolter (2007). This model makes use of readily available soil data for the watershed and calculates the hydraulic gradient at the grids from the information contained in the digital elevation model (DEM) of the watershed, assuming that the water table profile of the watershed follows closely its surface topography. However, for a watershed being drained by a subsurface drainage system, the hydraulic gradients at all locations of the flow domain would naturally not follow the surface topography and hence Schilling and Wolter's (2007) model probably would not be suitable for such situations. Jury (1975a, b) made use of the steady-state tile drainage solution of Kirkham (1958) to predict travel times of inert solute particles from the surface of a soil profile to subsurface tiles being installed at a specific depth in the soil, the soil being underlain by an impervious barrier. Kirkham and Affleck (1977) provided expressions for predicting travel times of solute from injection points to a well in a confined aquifer that fully penetrates the aquifer utilizing the piston flow assumption of solute movement along streamlines. Utilizing the same assumption, Cushman and Kirkham (1978) made use of the analytical model of Khan and Kirkham (1971) to work out mathematical expressions for predicting travel times of solutes to fully penetrating wells in a multilayered aquifer underlain by an impervious barrier, both for the cases when the outer boundary is a constant head zone and when it is a no flow one. Kirkham and Sotres (1978) mathematically studied the influence of unscreened casing length of a well in a phreatic aquifer on the travel times of solutes and observed the travel times to be positively correlated with casing depth of the well. Kirkham and Sotres (1979) provided a steadystate model for predicting flow into a tube well with a cover slab at the top of the well, the well being dug in a water table aquifer underlain by an impervious layer. Using the developed model, they then studied the influence of the slab cover at the top of the well on the travel times by taking resort to again the piston flow assumption of solutes moving along streamlines and observed that a well cover slab may increase travel times considerably in comparison to wells with no covers, particularly for particles being injected close to the edge of the cover.

The travel times of solute particles along a streamline are generally determined by performing appropriate integrals along the streamline using the piston flow hypothesis (Kirkham and Affleck 1977; Cushman and Kirkham 1978; Kirkham and Sotres 1978, 1979). The analytical evaluations of these integrals are mostly difficult to be achieved for many a flow and transport situations and hence are often done numerically. However, numerical evaluations of these integrals may also become quite demanding at times particularly when greater accuracy is desired; this is because for such situations the integrating space is needed to be divided into much finer parts. In view of the same, an effort is being made here to work out a relatively simple mathematical procedure for estimating accurately the travel times of solutes to a steady subsurface drainage system utilizing the hydraulic theory relevant to the system. The procedure involves evaluation of the coordinates (more the 
number, better will be the accuracy) falling on a streamline of interest by employing a Newton-Raphson procedure on the stream function expression of the relevant subsurface drainage model and then using the pertinent velocity functions of the model to translate these information to the travel times of the particles moving along the streamline. The procedure is general in nature and can be applied to work out travel times of solutes in diverse groundwater flow situations so long as suitable hydraulic models relevant to the studied situations are available. It is hoped that the mathematical procedure proposed here would prove to be particularly useful in estimating the probable time required for reclaiming a salt-affected soil utilizing a subsurface drainage system and in predicting the probable lag time of a contaminant to reach a stream in a watershed from its point of release vide subsurface flow.

\section{Mathematical analysis}

The travel time, $t$, of a solute particle moving in piston flow in a streamline in between two horizontal points $x_{1}$ and $x_{2}$ on it can be determined by considering and dividing an elemental horizontal path in between the points in the streamline with the horizontal pore velocity and then integrating the resultant expression within the limits $x_{1}$ and $x_{2}$ (Kirkham and Affleck 1977; Kirkham and Sotres 1978, 1979); thus, we have

$t=\int_{0}^{t} \mathrm{~d} t=\int_{x_{1}}^{x_{2}} \frac{\mathrm{d} x}{\left(v_{x} / \eta\right)}$,

where $v_{x}(x, y)$ is the horizontal velocity distribution at the coordinate location $(x, y)$ in the concerned portion of the streamline and $\eta$ is the porosity of the soil. As the mathematical expressions for the velocity fields are often quite complex in nature for many groundwater flow situations, analytical evaluation of integral Eq. 1 is often quite difficult and hence is mostly done numerically. However, numerical estimations of these integrals are also not easy and often require the integrating space to be divided into much finer parts if greater accuracy is to be achieved, particularly for flow situations where the velocity fields vary rapidly within small neighbourhoods in the flow domain. In view of the same, an attempt is being made here to work a mathematical procedure to estimate the travel times in a subsurface flow system without the necessity of evaluation of an integral like the one as shown in Eq. 1. The developed procedure is of a general nature and can be applied to a wide range of subsurface flow situations for estimating the travel times from known velocity and stream functions corresponding to these situations. We now introduce the procedure in its general form as shown below.

Suppose the hydraulics of a hydro-geological system is known and we are interested to find the travel time of an inert solute in between any two points (say, $A$ and $B$ ) in a streamline of interest in the concerned flow system. Let $x_{A B\left(C_{1}\right)}$ denote the horizontal distance between $A$ and $B$ in the said streamline, where $C_{1}$ represents the normalized value of the streamline $\left(0<C_{1}<1\right)$. If we now divide this horizontal domain into $N_{0}$ divisions, the horizontal separation between any two neighbouring points in the $C_{1}$ streamline would then naturally be $\Delta x=\left(x_{A B\left(C_{1}\right)} / N_{0}\right)$. If we consider the coordinates of the starting point at $A$ as $\left(x_{1\left(C_{1}\right)}, y_{1\left(C_{1}\right)}\right)$, where $x_{1\left(C_{1}\right)}$ and $y_{1\left(C_{1}\right)}$ are assumed known, then we have the relation among the horizontal coordinates of the different points as $x_{i+1\left(C_{1}\right)}=x_{i\left(C_{1}\right)}-\Delta x\left(1 \leq i \leq N_{0}\right)$. We now estimate the vertical ordinates $y_{i\left(C_{1}\right)}$, corresponding to each $x_{i\left(C_{1}\right)}$, where $1<i \leq N_{0}+1$. Towards this end, we apply the Newton-Raphson method (Scarborough 1966) starting from $x_{1\left(C_{1}\right)}$ and proceeding up to the end point $x_{N_{0}+1\left(C_{1}\right)}$ of the $C_{1}$ normalized streamline. Thus, to get the $y$-coordinate corresponding to $x_{2\left(C_{1}\right)}$, we use the relation

$$
\begin{aligned}
\theta\left[x_{2\left(C_{1}\right)}, y_{2\left(C_{1}\right)}\right] & =\theta\left[x_{2\left(C_{1}\right)}, y_{1\left(C_{1}\right)}+\Delta y\right] \\
& =\theta\left[x_{2\left(C_{1}\right)}, y_{1\left(C_{1}\right)}\right]+\Delta y\left(\frac{\partial \theta}{\partial y}\right)_{x_{2\left(C_{1}\right)}, y_{1\left(C_{1}\right)}}=0
\end{aligned}
$$

where

$\theta(x, y)=\psi^{n}(x, y)-C_{1}=0$

and $\psi^{n}(x, y)$ is the normalized streamline with coefficient $C_{1}$ for the concerned flow system. Equation 2 can be solved using Eq. 3 to evaluate $\Delta y^{(1)}$ [the superscript (1) above $\Delta y$ simply means that it is the estimate of $\Delta y$ at the end of the first step] and hence $y_{2\left(C_{1}\right)}^{(1)}$-the first estimate of $y_{2\left(C_{1}\right)}$ - since $y_{2\left(C_{1}\right)}^{(1)}=y_{1\left(C_{1}\right)}+\Delta y^{(1)}$. Taking this new $y_{2\left(C_{1}\right)}^{(1)}$ as the starting point for the next iteration, the same procedure like before can be followed to estimate the value of $y_{2\left(C_{1}\right)}$ at the end of the second iteration (i.e. $\left.y_{2\left(C_{1}\right)}^{(2)}\right)$. The iterations are continued till the absolute change of $y_{2}\left(C_{1}\right)$ between two successive steps (say, $j-1$ th and $j$ th steps) tends to zero, i.e. till $\left|y_{2\left(C_{1}\right)}^{(j)}-y_{2\left(C_{1}\right)}^{(j-1)}\right| \rightarrow 0$. When this happens, we will be finally having the value of $y_{2\left(C_{1}\right)}$ at $x_{2\left(C_{1}\right)}$. The whole algorithm can be repeated till all the $y_{i\left(C_{1}\right)}$ corresponding to each $x_{i\left(C_{1}\right)}\left(1<i \leq N_{0}+1\right)$ are being determined. Now, once the desired coordinate locations on the concerned streamline are being evaluated, we can next estimate the time taken by the particle to move in 
Fig. 1 A diagrammatic representation of the proposed iterative method for estimating the time of travel of an inert solute in between two points in a subsurface flow domain
Determine the horizontal separation between two points (say, $A$ and $B$ ) in a desired streamline between which the time of travel of an inert solute is sought to be determined along the said streamline in a hydro-geo system. It is assumed that the horizontal and vertical coordinates at the starting point $A$ is known in the concerned streamline

Divide the streamline passing through $A$ and $B$ into any desired number of division (more the number of division, better will be the accuracy), say $N_{0}$; this will lead to $N_{0}+1$ coordinate points (including points $A$ and $B$ ) in the concerned streamline over which the particle has to traverse on its journey from $A$ to $B$

Determine the horizontal and vertical coordinates of points falling in the concerned streamline from the point following the first point $A$ as the $x$ - and $y$-coordinates of this point is already assumed as known; whereas the horizontal coordinates of these points can be straightway calculated knowing the horizontal separation between adjacent points, the vertical coordinates can be determined by making use of the Newton-Raphson method utilizing the expression for the concerned stream function

Determine the horizontal and vertical velocities at each of these coordinate locations in the concerned streamline from the known velocity field pertaining to the system

Determine the distance between all adjacent points in the flow path of the solute particle and also determine the average pore velocity (average seepage velocity divided by porosity of the medium) in each of these intermediate flow paths (for $N_{0}+1$ coordinate points, obviously there

will be $N_{0}$ intermediate flow paths). The travel time of the solute between any two adjacent coordinate locations is simply the quotient between the separation distance of the coordinate locations and the average pore velocity applicable to the neighborhood of these locations

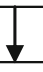

The travel time of the solute between $A$ and $B$ will then be simply the summation of all the intermediate times required by the particle to cover $N_{0}$ in-between flow paths between any adjacent coordinate locations using the velocity field of the flow domain. Assuming the velocity fluctuations in between the concerned adjacent coordinate points in the streamline to be a linear one, an assumption which will be justifiable so long $\Delta x \rightarrow 0$, the time of travel, $\Delta t_{i}$, of the particle in between $\left(x_{i\left(C_{1}\right)}, y_{i\left(C_{1}\right)}\right)$ and $\left(x_{i+1\left(C_{1}\right)}, y_{i+1\left(C_{1}\right)}\right)$ coordinates can be estimated as

$\Delta t_{i}=\frac{\Delta s_{i}}{\left(\bar{v}_{i}\right) / \eta}$,

where

$\Delta s_{i}=\sqrt{\left[(\Delta x)^{2}+\left(\Delta y_{i}\right)^{2}\right]}$,

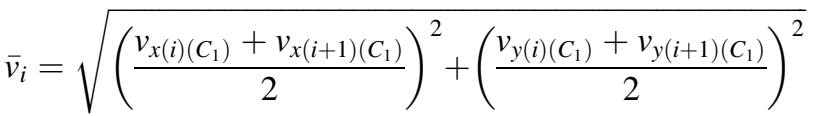

and $v_{x(i)\left(C_{1}\right)}, v_{x(i+1)\left(C_{1}\right)}$ and $v_{y(i)\left(C_{1}\right)}, v_{y(i)\left(C_{1}\right)}$ are the horizontal and vertical velocity components of the particle at the $i$ th and $(i+1)$ th coordinates, respectively, and $\eta$ is the porosity of soil. The procedure is repeated till the time of travel of the particle in between all the adjacent points starting from point $A$ to point $B$ in the $C_{1}$ streamline are being evaluated; the total travel time of the particle from $A$ and $B$ would then obviously be equal to the summation of all the intermediate time steps undertaken by the particle on its way in the $C_{1}$ streamline from $A$ to $B$. For ready reference, the entire procedure as just been described for estimating travel times of a non-reactive solute along a flow line in between any two desired points in a subsurface flow space is being graphically portrayed in Fig. 1. Patidar (2013) made use of this methodology to study fluid travel times for different subsurface drainage settings under both uniformly recharged and ponded conditions at the surface of a soil column. We would like to say again here that the proposed procedure is of a general nature and can be utilized to study travel time distributions of solutes in other hydro-geological settings as well so long as the pertinent hydraulic theories associated with these settings are 

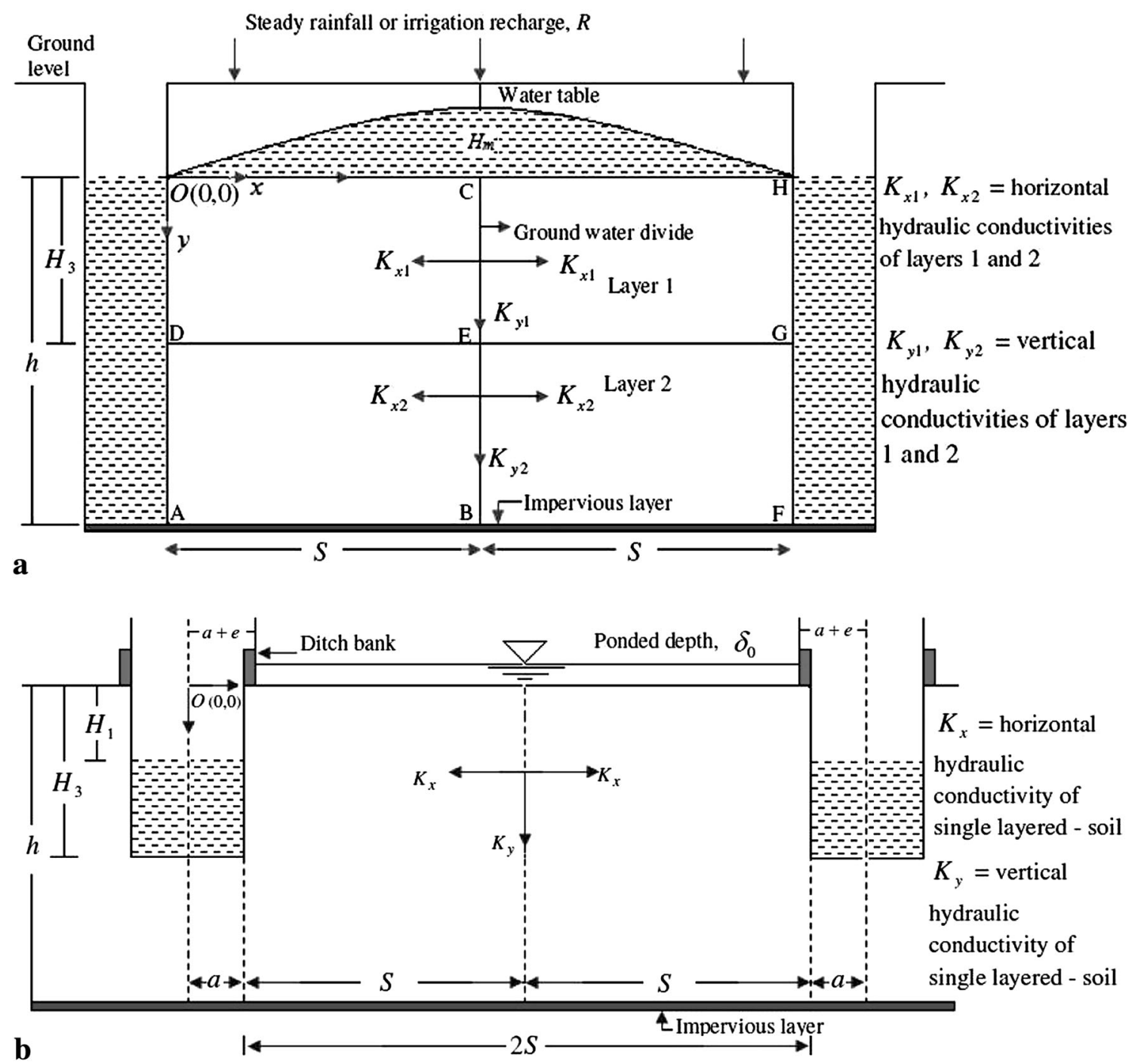

Fig. 2 a Geometry of a fully penetrating ditch drainage system in a two-layered soil receiving a uniform recharge at the surface of the soil. b Geometry of a partially penetrating ditch drainage system in a single-layered soil subjected to a uniform ponding depth of water at the surface of the soil

particles from the face $O C$ of Fig. 2a to the ditch drain on the left as obtained from the proposed method for a particular drainage situation of Fig. 2a with corresponding values obtained through direct integration of the horizontal velocity function (Eq. 1) pertaining to this flow situation. As can be seen from this figure, travel times obtained utilizing the method proposed here, even with only five divisions of the streamlines (i.e. $N_{0}=5$ ), are found to match very closely with the identical values obtained through numerical integration, thereby verifying that our developed procedure is a correct one.

From Figs. 4 and 5, we see that travel times are sensitive to the anisotropy ratio of the soil and follow approximately a logarithmic variation with time, particularly for particles moving from locations lying at relatively large distances here. Figure 3 shows comparison of travel times of solute 


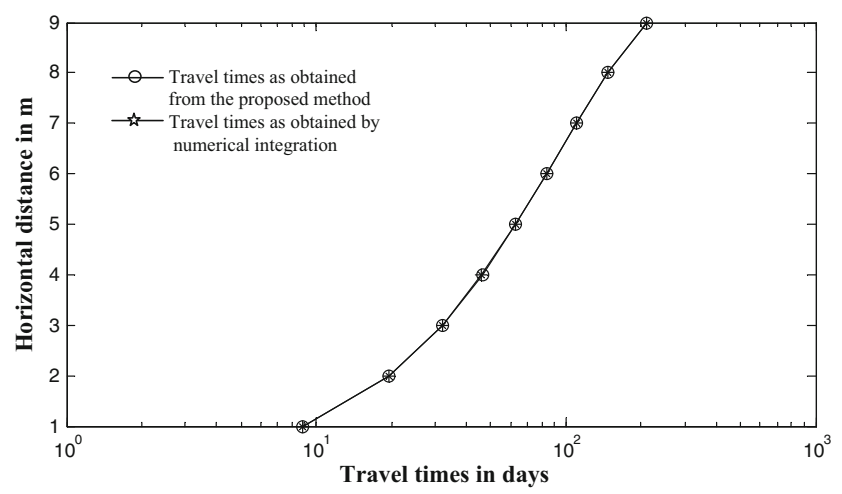

Fig. 3 Comparison of travel times as obtained from the proposed method (by taking $N_{0}=5$ ) with those obtained vide numerical integrations when the parameters of Fig. 2a are taken as $h=2 \mathrm{~m}$, $S=10 \mathrm{~m}, R=0.00659 \mathrm{~m} /$ day, $K_{x 1}=K_{x 2}=K_{y 1}=K_{y 2}=1.2 \mathrm{~m} /$ day

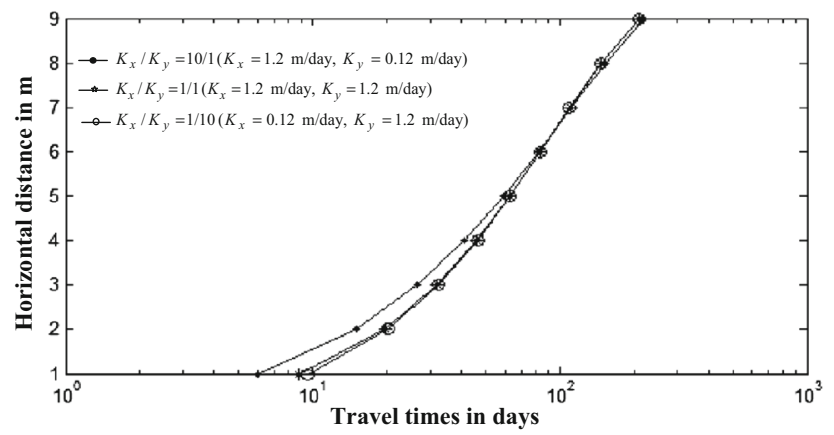

Fig. 4 Travel times for water particles originating at the face $O C$ of Fig. 2a to the left ditch when the parameters of problem are taken as $h=2 \mathrm{~m}, S=10 \mathrm{~m}$ and $R=0.00659 \mathrm{~m} /$ day and the conductivity ratios are as shown

from the ditch on the horizontal face $O C$ of Fig. 2a. It is to be noted that a somewhat similar logarithmic variation of the travel times with radial distance from the centre of a well in a single or multiple-layered aquifer was also observed by Cushman and Kirkham (1978), where the well is being assumed to be dug up to an impervious barrier and the aquifer being assumed to be subjected to a uniform recharge on a horizontal radial surface meeting the archshaped water table at the well face. It can also be observed from Fig. 4 that the travel times are sensitive to the anisotropy ratio of a soil, particularly for particles moving to the ditches from locations lying close to the drains in a drainage space with a high anisotropy ratio. Figure 5a, b show that travel times are highly sensitive to the magnitude of recharge at the surface of the soil; as may be observed, for these flow situations, reducing the recharge rate by half makes the travel times to approximately increase by two times for most of the particles originating on the face $O C$ of Fig. 2a. Further, it can also be observed from Fig. 5a, c that the travel times are also responsive to the depth of the ditch drains and increase with the increase in depth of the drains, the effect being more pronounced for particles moving to the drains from locations lying further away from the ditches. Figure $6 a, b$ show that travel times are influenced by the directional conductivities of both the layers of a twolayered soil. The horizontal conductivities have a tendency to flatten the streamlines, and the vertical conductivities tend to move the streamlines deeper into the ground. Thus, among other factors remaining the same, an increase in the horizontal conductivities of the layers not only causes the travel times of the particles to decrease but also causes the vertical domain of influence of the streamlines to decrease at the same time; this effect will be more pronounced in drainage situations where the horizontal conductivities of the layers predominate much over the vertical conductivities of the layers. Thus, leaching of a saline soil by subjecting it to a uniform recharge at the surface and draining the salt-enriched leached water with a network of subsurface ditch drains would result in much more deeper areas to be leached if the soil profile is having a relatively higher vertical hydraulic conductivity as compared to the horizontal conductivity of the soil. This would, however, result in a much longer time of leaching as compared to situations where the horizontal conductivity of the soil is high. The presence of a gravel layer just above the impervious layer in a uniformly recharged ditch drainage system has a significant influence on the streamline distribution patterns in a subsurface flow space and hence on the travel times of particles travelling along these flow lines (Fig. 6c). The gravel layer exhibits a tendency to short circuit the streamlines resulting in most of the streamlines now meeting the ditches through the gravel layer with only particles starting from locations close to the drains meeting them directly. It is also interesting to see from Fig. $6 \mathrm{c}$ that for the considered uniformly recharged ditch drainage system, the travel times of solute are actually decreasing with the increase of distance from the face of the ditch, and the path lines are nearly straight lines at locations midway between the drains.

For a partially penetrating ditch drainage system being subjected to a uniform ponding field, the travel times of particles from the surface of the soil to the drains are found to be influenced by the anisotropy ratio of the soil, width, depth of penetration and water level heights of the drains (Figs. 7, 8) and the depth of the water head provided at the surface of the soil. From Fig. 7a, b, it can be seen that the travel times decrease with the increase of ponding depth and are relatively much smaller for particles moving to the drains from locations close to the drains than those coming from areas further away from the drains. The travel times are also observed to decrease with the decrease in the level of water in the ditches and with the increase in width of the ditches, particularly for situations where the spacing between the ditches is relatively small and the anisotropy ratio of the soil 
Fig. 5 Normalized streamlines and travel times for water particles originating at the face $O C$ of Fig. 2a when the parameters of the problem are taken as shown
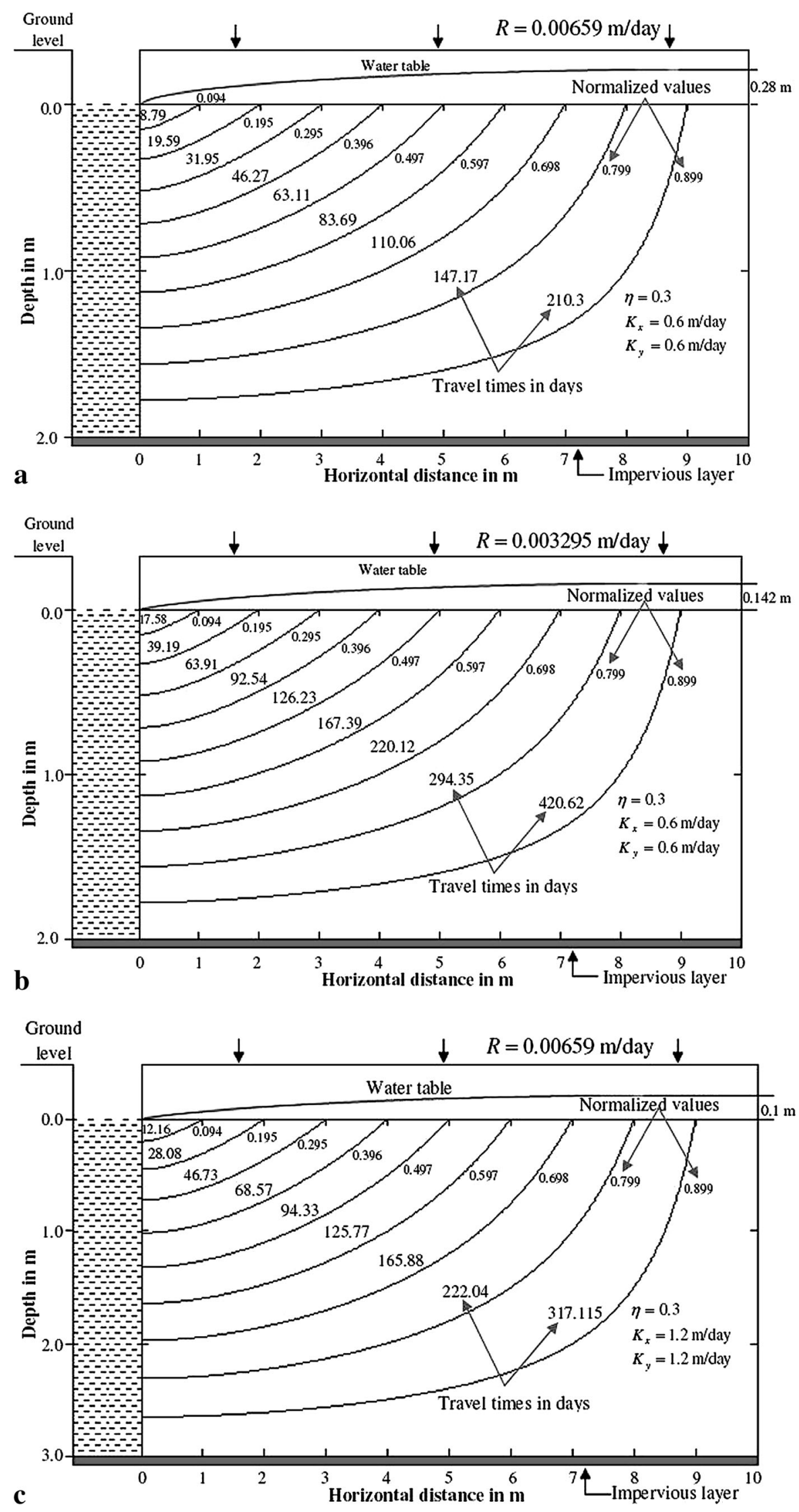

c 
Fig. 6 Normalized streamlines and travel times for water particles originating at the face $O C$ of Fig. 2a when the parameters of the problem are taken as shown
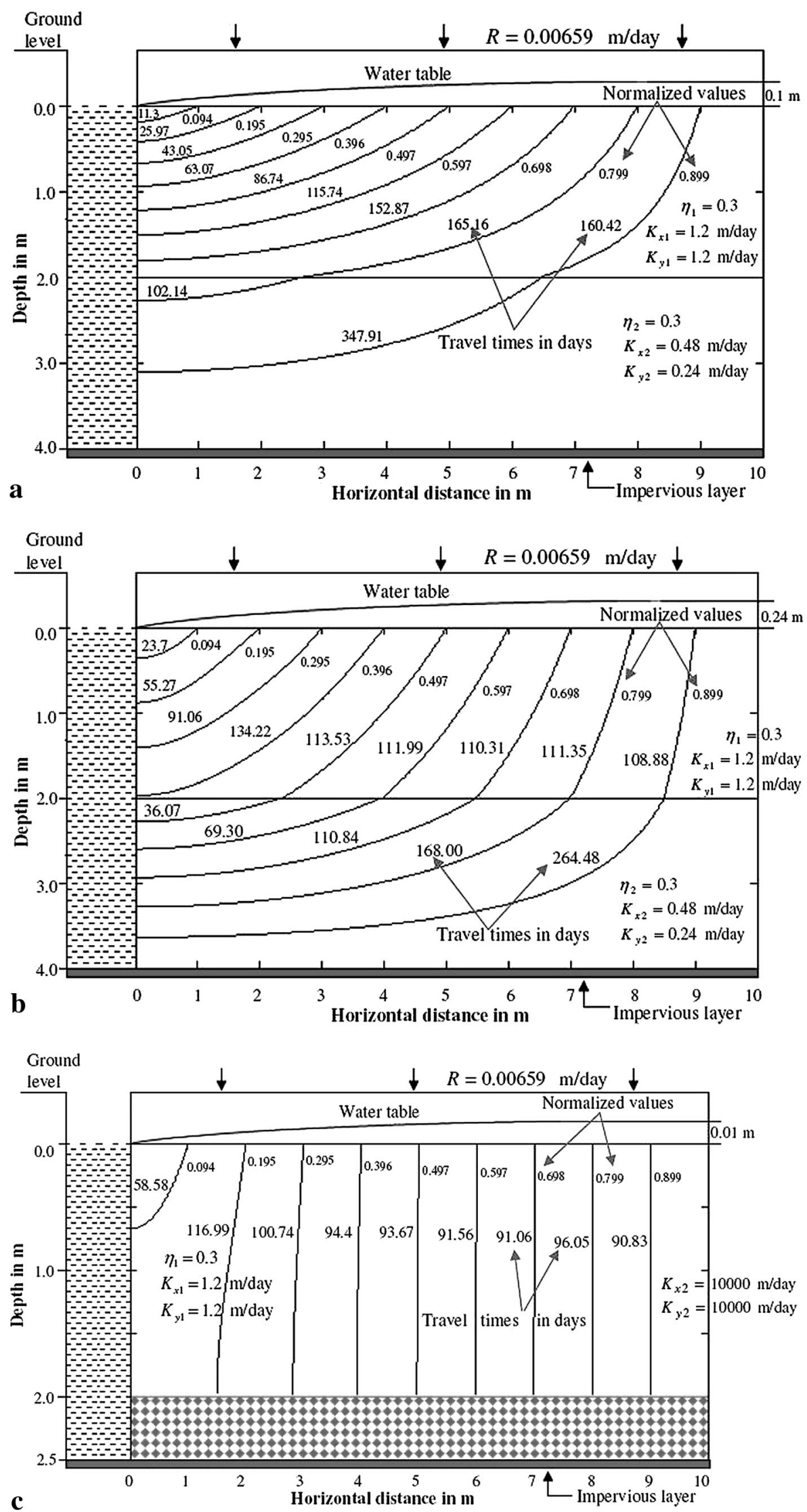
Fig. 7 Normalized streamlines and travel times for water particles originating at the surface of the ponded field of Fig. $2 b$ to the left ditch when the parameters of problem are as shown
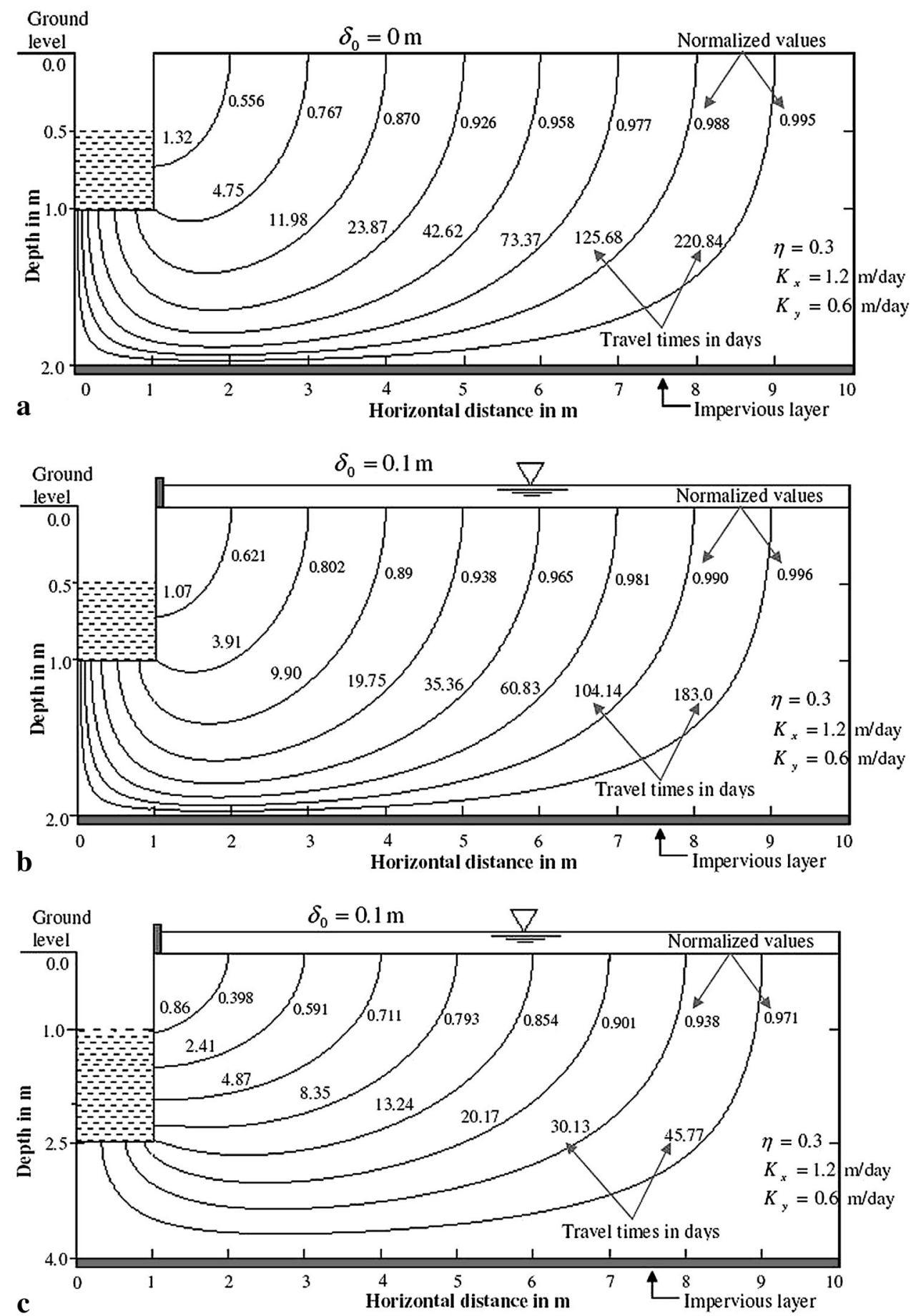

is relatively high. The increase in spacing between the ditches is seen to increase the travel times of particles, particularly for particles traversing in streamlines originating from areas located away from the ditches (Fig. 8).

Reclamation of a salt-affected soil by a uniformly ponded ditch drainage system show that leaching is mostly confined to areas lying close to the ditches, and the quantity of water seeping through regions adjacent to the drains is much higher than that seeping through areas away from the drains. However, the uniformity of leaching through a uniformly recharged ditch drainage system is relatively better than that of a ponded ditch drainage system as the streamlines in the former case are much more uniformly distributed in a concerned drainage space than that of streamline distributions arising out of a ponded drainage system. Further, the travel times of solute particles moving to the drains starting from locations further away from the drains in both the uniformly recharged as well as uniformly 


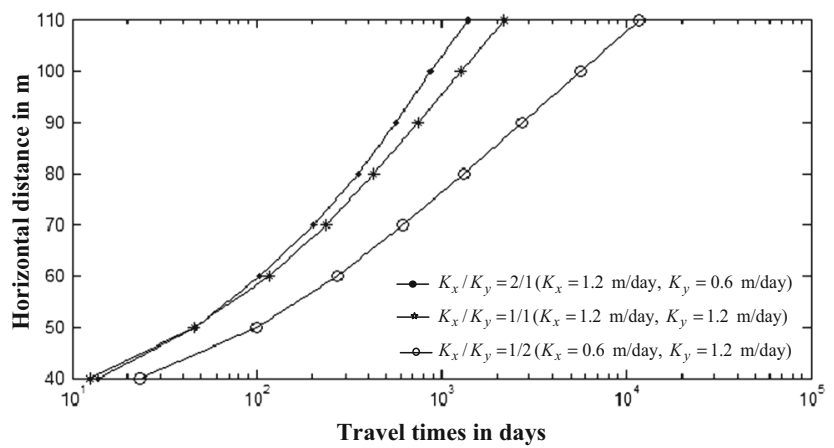

Fig. 8 Travel times for water particles originating at the surface of the ponded field of Fig. $2 \mathrm{~b}$ to the left ditch when the parameters of problem are taken as $h=30 \mathrm{~m}, H_{3}=15 \mathrm{~m}, H_{1}=5 \mathrm{~m}, a=30 \mathrm{~m}$, $S=90 \mathrm{~m}$ and $\delta_{0}=0 \mathrm{~m}$

ponded drainage systems are much higher than those of particles starting from locations close to the drains. Thus, for the uniformly ponded drainage situation of Fig. 7b, as may be observed, about $89 \%$ of the flow to the ditches is being contributed from areas lying around $4 \mathrm{~m}$ from the centre of the ditches, and the time taken for a particle to traverse in the 0.996 normalized streamline to the ditch is much higher (183 days) than that of a particle moving along the 0.621 normalized streamline (1.07 days). From Fig. 5, it can be seen that for a uniformly recharged subsurface drainage system also considerable time is required by particles to move to the drains starting from locations lying further away from the drains. Thus, the reclamation time of an area lying in the immediate vicinity of the drains of a subsurface drainage system may be relatively much less as compared to cleaning time of a zone located further away from the ditches. Another important point worth noting here is that a contaminant released at a relatively larger distance from a stream or channel may require a large time to actually reach the stream and thus may remain inert in the subsurface for a much larger time as compared to a contaminant being released close to the stream.

The flow situation of Fig. $2 b$ can also be visualized as that of flow to a stream (or river) of rectangular cross section from a flooded field of uniform ponding depth, if the width of the ditch drains $a$ is given a large value. The streamline and travel time distribution for such a flow scenario is then expected to give an idea about to what extent and for how long the base flow hydrograph of a stream in a watershed is being influenced by a flood of known magnitude in the watershed. For the flow situation of Fig. 8, a water particle falling at a distance of $50 \mathrm{~m}$ from the stream takes about 46 days for it to arrive at the stream when the anisotropy ratio of the soil is $2: 1$ ( $K_{x}=1.2 \mathrm{~m} /$ day, $K_{x}=0.6 \mathrm{~m} /$ day), the corresponding figures, however, turn out to be about 100 days when the anisotropy ratio is being reversed, i.e. 1:2
$\left(K_{x}=0.6 \mathrm{~m} /\right.$ day, $K_{x}=1.2 \mathrm{~m} /$ day $)$. Thus, it is interesting to note that a mere reversal of anisotropy ratio from $2: 1$ to 1:2 for the flow situation of Fig. 8 brings about approximately a change of 2.17 times of the travel time values of a water particle moving through subsurface flow to the stream starting from a location situated at a surficial distance of $50 \mathrm{~m}$ from the stream. It is also worth noting that the corresponding travel time values for a particle starting from a location situated at a distance of $100 \mathrm{~m}$ from the edge of the stream are about 872 days (2.4 years) and 5,667 days ( 15.5 years), respectively, and for a particle starting at a surficial distance of $110 \mathrm{~m}$ from the stream, the corresponding figures are about 1,385 days (3.8 years) and 11,651 days (31.9 years), respectively. These are important information as they provide insights about the time span for which the base flow hydrograph of a stream in a watershed is being influenced by a flood surge of a known magnitude in the watershed. They also throw light on the time taken by a contaminant plume to move from its point of inception in a subsurface system to the recipient streams or drains; as can be observed from the test example of Fig. 8, this duration may be inordinately high, particularly for watersheds where the vertical hydraulic conductivity predominates by a large margin over that of the horizontal hydraulic conductivity of the soil.

Thus, from our analysis above, we see that the travel times in a homogeneous and anisotropic soil being drained by a network of equally spaced ditch drains underlain by an impervious stratum and receiving a steady rainfall or irrigation recharge are inversely correlated with the recharge rate and the directional conductivities of the soil. An increase in the depth of an aquifer increases the travel times and same is the observation when the spacing between ditches is made to increase. The nature of the underlying layer of a uniformly recharged ditch drainage system also appear to have a pivotal role in deciding the travel time distributions in the considered subsurface space; the presence of a gravel substratum just above an impervious barrier causes the travel times to reduce drastically in comparison to situations where the underlying layer is being composed of the impervious layer alone. A high vertical conductivity of the layers has a tendency to uncoil the streamlines and push them downward, whereas a high horizontal conductivity of the layers exhibits a tendency to wound and flatten them. Thus, an increase in the vertical conductivity of the layers would result in relatively deeper areas of the soil profile being covered by the flow lines, whereas an increase in the horizontal conductivity of the layers would result in relatively shallower areas being covered by the flow lines. Further, a high anisotropy ratio of a uniformly recharged ditch drainage system causes the travel times to decrease and a low anisotropy ratio of the soil causes the travel times to increase, provided all the 
other flow parameters of the problem are kept the same. In case of a partially penetrating ditch drainage system receiving water from a ponded field, the streamlines have been observed to be poorly distributed along the flow profile with most of the seepage to the drains being confined to locations close to the drains. Compared to such a flow system, streamlines for a uniformly recharged ditch drainage system have been observed to be more uniformly distributed. However, in both the systems, the travel times of particles originating from locations away from the drains have been seen to be much higher than those originating from locations close to the drains. By subscribing a high value of the width of the ditch drains, the proposed iterative method can also be used to study travel times of water particles from a flooded field to a stream or river in a watershed. Thus, the method proposed here can also be used for predicting migration time of pollutants to a stream or river from its surroundings through subsurface flow in a watershed. It is also worth noting that the proposed procedure totally eliminates the necessity of evaluation of any integrals while determining the solute travel times in a subsurface system and may thus, in comparison to the existing methods, prove to be relatively simple to apply for working out the solute travel time distributions in many hydro-geo situations.

Open Access This article is distributed under the terms of the Creative Commons Attribution License which permits any use, distribution, and reproduction in any medium, provided the original author(s) and the source are credited.

\section{References}

Barua G, Alam W (2013) An analytical solution for predicting transient seepage into ditch drains from a ponded field. Adv Water Res 52:78-92

Barua G, Tiwari KN (1995) Theory of seepage into auger holes in homogenous anisotropic soil. J Hydrol 167:1-22

Barua G, Tiwari KN (1996) Theories of ditch drainage in layered anisotropic soil. J Irrig Drain Eng 122(6):321-330

Brown LC, Schmitz BM, Batte MT, Eppley C, Schwab GO, Reeder RC, Eckert DJ (1998) Historic drainage, tillage, crop rotation and yield studies on clay soils in Ohio. In: Proceedings of the 7th annual drainage Sympo, pp 456-464

Chahar BR, Vadodaria GP (2011) Steady subsurface drainage of ponded surface by an array of parallel ditches. J Hydrol Eng 17(8):895-908

Cushman J, Kirkham D (1978) Solute travel times to wells in single or multiple layered aquifers. J Hydrol 37:169-184

Davis DM, Gowda PH, Mulla DJ, Randall GW (2000) Modelling nitrate nitrogen leaching in response to nitrogen fertilizer rate and tile drain depth or spacing for southern Minnesota, USA. J Environ Qual 29:1568-1581

Dils RM, Heathwaite AL (1999) The controversial role of tile drainage in phosphorus export from agricultural land. Water Sci Technol 39:55-61

Haitjema HM (1995) On the residence time distribution in idealized groundwatersheds. J Hydrol 172:127-146
Heathwaite AL, Dils RM (2000) Characterising phosphorus loss in surface and subsurface hydrological pathways. Sci Tot Environ 251(252):523-538

Jury WA (1975a) Solute travel-time estimates for tile-drained fields: I. Theory. Soil Sci Soc Am Proc 39:1020-1024

Jury WA (1975b) Solute travel-time estimates for tile-drained fields:II. Application to experimental studies. Soil Sci Soc Am Proc 39:1024-1028

Jury WA, Weeks LV (1978) Solute travel-time estimates for tiledrained fields: III. Removal of a geothermal brine spill from soil by leaching. Soil Sci Soc Am Proc 425:679-684

Khan MY, Kirkham D (1971) Spacing of drainage wells in a layered aquifer. Water Resour Res 7(1):166-183

Kirkham D (1958) Seepage of steady rainfall through soil into drains. Trans Am Geophys Union 39:892-908

Kirkham D, Affleck SB (1977) Solute travel times to wells. Groundwater 15(3):231-242

Kirkham D, Sotres MO (1978) Casing depths and solute travel times to wells. Water Resour Res 14(2):237-243

Kirkham D, Sotres MO (1979) Influence of cover slab diameter on solute travel time to wells. Water Resour Res 15(4):941-948

Kladivko EJ, Grochulska J, Turco RF, Van Scoyoc GE, Eigel JD (1999) Pesticide and nitrate transport into subsurface tile drains of different spacings. J Environ Qual 28:997-1004

Kladivko EJ, Frankenberger JR, Jaynes DB, Meek DW, Jenkinson BJ, Fausey NR (2004) Nitrate leaching to subsurface drains as affected by drain spacing and changes in crop production system. J Environ Qual 33:1803-1813

Kroger R, Cooper CM, Moore MT (2008) A preliminary study of an alternative controlled drainage strategy in surface drainage ditches: low grade weirs. Agric Water Manag 95(6):678-684

Martinez Beltran J (1978) Drainage and reclamation of salt effected soils in the Bardenas area, Spain. ILRI Publications 24, Wageningen, The Netherlands

Meals D, Dressing S (2006) Lag time in water quality response to land treatment. NWQEP Notes No. 122, NC State University Coop Extension Rayleigh, NC

Patidar MK (2013) An iterative method for estimating travel times of water particles in a subsurface flow system. Unpublished M. Tech thesis, Department of Civil Engineering, Indian Institute of Technology Guwahati, Assam, India

Rao KVGK, Leeds-Harrison PB (1991) Desalinization with subsurface drainage. Agric Water Manag 19(4):303-311

Scarborough JB (1966) Numerical mathematical analysis, 6th edn. Oxford and IBH Publishing Company Private Limited, New Delhi, pp 203-207

Schilling KE, Helmers M (2008) Effects of subsurface drainage tiles on streamflow in Iowa agricultural watersheds: Exploratory hydrograph analysis. Hydrol Process 22:4497-4506

Schilling KE, Libra RD (2003) Increased baseflow in Iowa over the second half of the 20th century. J Am Water Res 39(4):851-860

Schilling KE, Wolter CF (2007) A GIS-based groundwater travel time model to evaluate stream nitrate concentration reductions from land use change. Environ Geol 53:433-443

Schilling KE, Jindal P, Basu NB, Helmers MJ (2012) Impact of artificial subsurface drainage on groundwater travel times and baseflow discharge in an agricultural watershed, Iowa (USA). Hydrol Process 26:3092-3100

Youngs EG (1994) Seepage to ditches from a ponded surface. J Hydrol 161:145-154

Youngs EG, Leeds-Harrison PB (2000) Improving efficiency of desalinization with subsurface drainage. J Irrig Drain Eng 126(6):375-380

Zaslavsky D (1979) Drainage for salt leaching. In Proceedings of the International Drainage Workshop, vol 25. International Institute for Land Reclamation and Improvement, Wageningen 